\title{
Blueprint of Permanent Education Number (PEN) Card for Reducing Paper Usage Ratio in Education and Job Sector
}

\author{
Rahul Kumar Ghosh, Jayanta Kumar Das, Anirban Das
}

\begin{abstract}
Several decades ago, it was a thought that usage of paper will reduce with the advancement of technology but rather it has been increased through the printing/photocopying of different documents specifically in education and job sector, as there is a much need of paper consumption, which in turn leading a perceptible environmental impacts like air pollution, deforestation, greenhouse gas emissions, etc. This study intends to develop a concept where entire documents (education and job sector) will be digitalized. Furthermore, this study aims to propose a framework that will be ensuring the reduction of paper consumption as well as condense the negative environmental impacts. Besides, this paper focuses to study the paper usage estimation in the education sector (enrolment of various levels) and job recruitment process as well as the effect of the paper industry on the environment. It is observed that the average paper used yearly 659078400 by an Indian. This study adopted a qualitative approach by embracing some case studies moreover observation methods have been used to obtain the outcomes. This study concludes that using the PEN (Permanent Education Number) of an induvial, fetching data will be erased as the data will remain digitalized, which furnishes several advantages i.e. reducing fraud, increase the data lifespan, reducing of manual paperwork, saving the environment, etc. Henceforth, the digitalization of enrolment in the education sector and recruitment in the service sector is indispensable to restraint the upsurge of paper used along with decrease the subsequent environmental impact.
\end{abstract}

Keywords: PEN, Environmental Impact, Paper Consumption, Digitalization, Education Sector.

\section{INTRODUCTION}

At present, inside your wallet, you presumably have two or three credit cards, an ID card, an ATM card, and possibly a couple of other plastic cards. Without acknowledging it, these plastic cards have turn out to be an important part of your life. Consider a couple of situations where one uses plastic cards nowadays:

$\begin{array}{ll}\text { - } & \text { As ID card } \\ \text { - } & \text { As ATM/Debit card } \\ \text { - } & \text { As Credit card } \\ \text { - } & \text { As Access control card } \\ \text { - } & \text { As Health card } \\ \text { - } & \text { As Toyalty program card } \\ & \text { Aransportation card etc. }\end{array}$

Revised Manuscript Received on 14, October 2019.

Rahul Kumar Ghosh, Information Technology, Seacom Skills University, Bolpur, WestBengal, India.(Email: rahulghosh.0101@gmail.com)

Dr. Jayanta Kumar Das, Information Technology, Seacom Skills University, Bolpur, WestBengal, India.(Email: jkdas1@yahoo.com)

Dr. Anirban Das, Computer Science \& Engineering, University of Engineering \& Management, Kolkata, India.(Email: anirbandas@live.com)
A large portion of these plastic cards is generally magnetic stripe cards. Despite their tremendous popularity, magnetic stripe cards experience the crucial weakness: information stored on them can be easily read and altered by somebody with access to the correct sort of hardware. Accordingly, confidential information, for example, a PIN or a password can't be stored on them and a transaction host (POS device/ATM) should go online to confirm the PIN, and this in most European and Asian nations is tedious and exorbitant. The improvement of smart cards, alongside fast advances in cryptography, has brought an explanation to the above - mentioned problem [1] [2].

The smart card is a plastic card with an installed microchip (typically little gold - shaded metal module), fit for storing a lot of information plus performing essential computing activities. Maximum smart cards look like a standard credit card [3]. The eventual fate of smart cards is subjected to the application of multi-application cards followed by overcoming the basic mindset that smart cards are only a strategy for doing a payment.

According to the advanced technologies developed in the field of information technology, most of us can derive the conclusion that information technologies are evolving at an incredible rate that enables us to modernize, improve and invest more in the last decade. Undoubtedly, this revolution currently does not lacks any aspect of human life [4].

Beginning with the universities to schools, an uprising in the technology is captivating the shape. The time when ordinary jobs like student attendance, faculty attendance, class register, etc. were manually handled, is now done with the help of the system.

A new part to consider is the manual admission procedure for students. Nowadays the higher education institutions have accepted the online admission procedure, but students must also submit their previous education credentials in the form of a photocopy. Moreover, they need to show the original certificates physically for the confirmation of the authenticity to complete the admission procedure. Another priority would be hiring in the public and private sectors. Until recently, the general recruitment process in both sectors began with the online application form, followed by the online/offline exam and the declaration of results. However, apart from the procedure mentioned above, it is necessary to submit education credentials in the form of a photocopy medium, followed by the verification of the same [5]. 


\section{BLUEPRINT OF PERMANENT EDUCATION NUMBER (PEN) CARD FOR REDUCING PAPER USAGE RATIO IN EDUCATION AND JOB SECTOR}

In both circumstances, students and applicants must physically present their original certificates to verify their authenticity and complete the admission/hiring process. This puts students and candidates at risk of deteriorating or losing their original testimonies. Regardless of this, the cost of photocopying and the need for photocopy paper is an important issue of the "green now" concept. Finally, the production of counterfeit certificates for admission procedures in the field of higher education and the recruitment procedure is widespread. These situations are rarely noticed at an early stage because photocopies are compared to the original testimonies, which itself is fake [5].

Recently, in 2017, four people, including two women, were arrested for selling fake university degrees and mark sheets. They ran this racket for three years. From grade 12 to MBA, they provided false certificates and testimonials. So far, about three hundred false testimonies have been distributed [6]. In the year 2016 "The Times of India" newspaper stated that at least one hundred and twenty-two students had procured a fake degree in Rajkot. The racket is spread across the country and the accused used to make fake degree certificates of twenty different universities and three school boards and aging this racket was also running for the last three years [7]. Several incidents were reported on the internet and leading newspapers regarding the fake education credentials and testimonials staring from class 12 certificate to DGCA test certificate and commercial pilot license.

India is having a bulky student population as well as a huge number of employers seeking candidates. Moreover, the issues were mentioned above could be addressed to a greater extent with the digitalization of the education credentials and testimonials as well as storing them directly in the government data repository. Therefore, the number of photocopy submission for admission and recruitment procedure can be reduced and the possibility of producing fake credentials and testimonials is negligible as the education boards themselves will create the digital credentials and testimonials along with storing it in data repository which will be under the surveillance of government. Adopting this method the education boards and the recruiters can easily tally the credentials and testimonials as submitted by the students or candidates with the data present in the data repository respectively.

\section{EDUCATION ENROLMENT AT VARIOUS LEVELS AND JOB RECRUITMENTS}

The enrolment through all modes (regular \& distance) at various levels is 345.8 lakhs in India. The highest portion of enrolment which is $81 \%$ is at the undergraduate level, followed by postgraduate with $9.1 \%$ and diploma with $8.2 \%$ while other levels (Ph.D., M.Phil. PG Diploma, certificate \& Integrated) are forming only $1.7 \%$ of the total enrolments. India has the second-largest higher education system in the world in terms of absolute enrolments, after China [8]. The yearly job recruitment in the public \& private sectors is nearly two hundred and ninety lakh in India as of 2011 as reported by the Ministry of Labour \& Employment, Director General of Employment and Training.

\section{PAPER USAGE ESTIMATION: ENVIRONMENTAL ENDANGERMENT}

After having the aforementioned data from the previous section, if the instance of admission process is considered at undergraduate level in various higher education institute, it can be understood that a higher secondary $\left(12^{\text {th }}\right.$ standard $)$ completed students at the time of applying for admission in a single college at undergraduate level has to submit approximately a total of eight photocopies of different education credentials and testimonials taking in account of two admit cards $\left(10^{\text {th }} \& 12^{\text {th }}\right.$ standard $)$, two pass certificate $\left(10^{\text {th }} \& 12^{\text {th }}\right.$ standard $)$, two mark sheets $\left(10^{\text {th }} \& 12^{\text {th }}\right.$ standard), one school leaving certificate $\left(12^{\text {th }}\right.$ standard $) \&$ one migration certificate $\left(12^{\text {th }}\right.$ standard $)$. On the other hand for the instance of the job recruitment procedure, a candidate needs to submit approximately fifteen photocopies (taking in account of previously mentioned eight photocopies plus six mark sheets of six semesters a one pass certificate) of different education credentials and testimonials.

If $81 \%$ of students out of 345.8 lakh are enrolling for undergraduate program and two hundred and ninety lakh candidates are getting recruited in public as well as private sector organizations, then approximately the number of papers getting used yearly can be calculated as follows:-

\begin{tabular}{|c|c|c|c|c|}
\hline Total Enrollment & $x$ & UG Enrolment \% & $=$ & Total no. of Students \\
\hline 34580000 & $X$ & $81.00 \%$ & $=$ & 28009800 \\
\hline $\begin{array}{l}\text { Total UG enrolling } \\
\text { students }\end{array}$ & $x$ & $\begin{array}{l}\text { Avg no. of photocopies } \\
\text { submitted }\end{array}$ & $=$ & Paper used by stude \\
\hline 28009800 & $X$ & 8 & $=$ & 224078400 \\
\hline Avg. no, of recruitment & X & $\begin{array}{l}\text { Arg, no. of photocopies } \\
\text { submitted }\end{array}$ & $=$ & $\begin{array}{l}\text { Paper used by } \\
\text { candidates }\end{array}$ \\
\hline 29000000 & $X$ & 15 & $=$ & 435000000 \\
\hline $\begin{array}{l}\text { Paper used by students } \\
224078400\end{array}$ & $\begin{array}{l}+ \\
+\end{array}$ & $\begin{array}{l}\text { Paper used by candidates } \\
\qquad 35000000\end{array}$ & $\begin{array}{l}= \\
=\end{array}$ & $\begin{array}{l}\text { Avg. paper used yearly } \\
659078400\end{array}$ \\
\hline
\end{tabular}

Figure 1. Approximate Yearly Paper Usage Estimation by Indian

As it can be seen from Figure 1 that an average of nearly sixty-six cores of papers are used by Indian students $\&$ jobseeking candidates yearly and the number of papers used to get increased when the students and candidates are applying in more than one colleges or job for seeking admission or job respectively at undergraduate level which is perhaps quite common among the students and candidates

\section{IMPACT OF PAPER AND PAPER INDUSTRY ON ENVIRONMENT}

A single tree can produce about 80,500 sheets of paper [9]. As a result, approximately 8,190 trees are required to meet the annual paper requirements for Indian students (undergraduate enrolling only), and this applies when applying to one university. A normal A4 sheet comprises 80 
$\mathrm{g} / \mathrm{m}^{2}$ of paper [10] and weighs almost $5 \mathrm{~g}$ [11]. These types of paper are commonly used by photocopiers (Xerox) [12]. Paper production is the third-largest industry and accounts for almost $12 \%$ of the total energy of the manufacturing sector [13].

In this digital age, the global environmental footprint is huge. Nearly 4 billion (400 corers) of trees worldwide are cut down each year for papermaking, representing approximately $35 \%$ of all harvested trees. Global paper consumption has increased by $400 \%$ in the last 40 years [14]. The increase in universal consumption and the struggle to provide cheap paper has led to continued market pressure that has led manufacturers to previously non-industrialized forest areas and transformed the diversity of carbon-rich natural forests into wild tree plantations and sterile plantation [4].

The most recent dangers to the world are not plastic bags, it's the annual pieces of paper, tons of discarded paper that printers and photocopiers throw away in a matter of hours. Three hundred and twenty-four liters of water are used to produce one kilogram of paper and moreover, ten liters of water are required to produce one piece of A4 paper [13]. It should be noted that a single tree can produce enough oxygen for at least three persons to breathe [15]. The air pollution is an important environmental concern in the pulp and paper industry. The main emissions tracked include $\mathrm{CO}$, $\mathrm{SO}_{2}$, NO and other volatile organic compounds and particulates. Water is vigorously used in the papermaking industry. A typical Kraft mill requires approximately twenty thousand gallons per ton of pulp [16].

\section{PROPOSED MODEL FOR INTENTION TO ADOPT MODEL}

The proposed research model is based on the model used by Lee's research in 2003 [17] to compare the introduction of smartcards at the Universities of Singapore and Australia. Another use was in a study by Aubert and Hamel in 2001 [18] the aim was to evaluate the factors that influence the introduction of a smart card in the medical field. Finally, little alteration is done to the model for forming the hypothesized model of Intention to Adopt. Figure 2 shows a schematic view of this model. The proposed model is a combination of TAM models, Innovation Diffusion Theory and PCI [5].

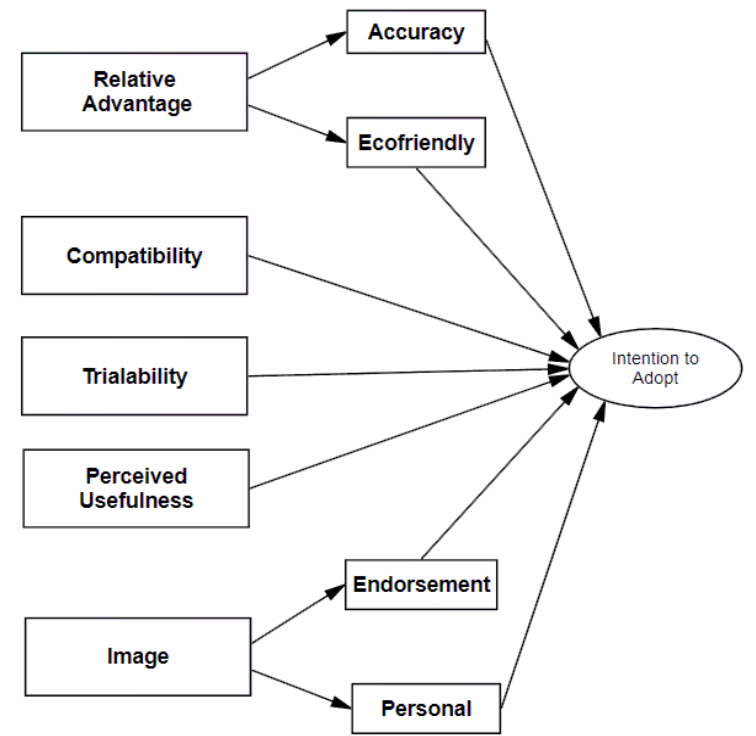

Figure 2. Hypothesized Model of Intention to Adopt. [5]

\section{PROPOSED FRAMEWORK OF PEN}

The educational card contains all the educational evidence of the students and can only be used to justify all testimonials of a particular student. The education card will be presented to Grade 10 students at the time of registration for the exam. Subsequently, the authorized entity periodically updates the card when a particular student obtains new credentials and E-credential will be available at any time to the official. Students should not have to carry their original certificates with them for the verification process [19].

According to the proposed model, the paper consumption rate falls dramatically and, apart from that, students also get benefited financially because they need to submit a single photocopy of the PEN card in place of eight photocopies of previously obtained credentials. The PEN card will be having all certificates and testimonials electronically stored as well verified, it will be having a unique identification number of ten characters printed on it. With this identification number, the records of a particular student can be obtained from the authorized agency/organization [19].

The proposed framework can solve many management problems, such as student enrolment and credential management. Besides, the introduction of the PEN card will transform the various Indian education systems into a single centralized education system (CES) while protecting the environment. The Conceptual Model is given in Figure 3. The Data Flow Diagram of the "PEN Card" is shown in Figure 4. 


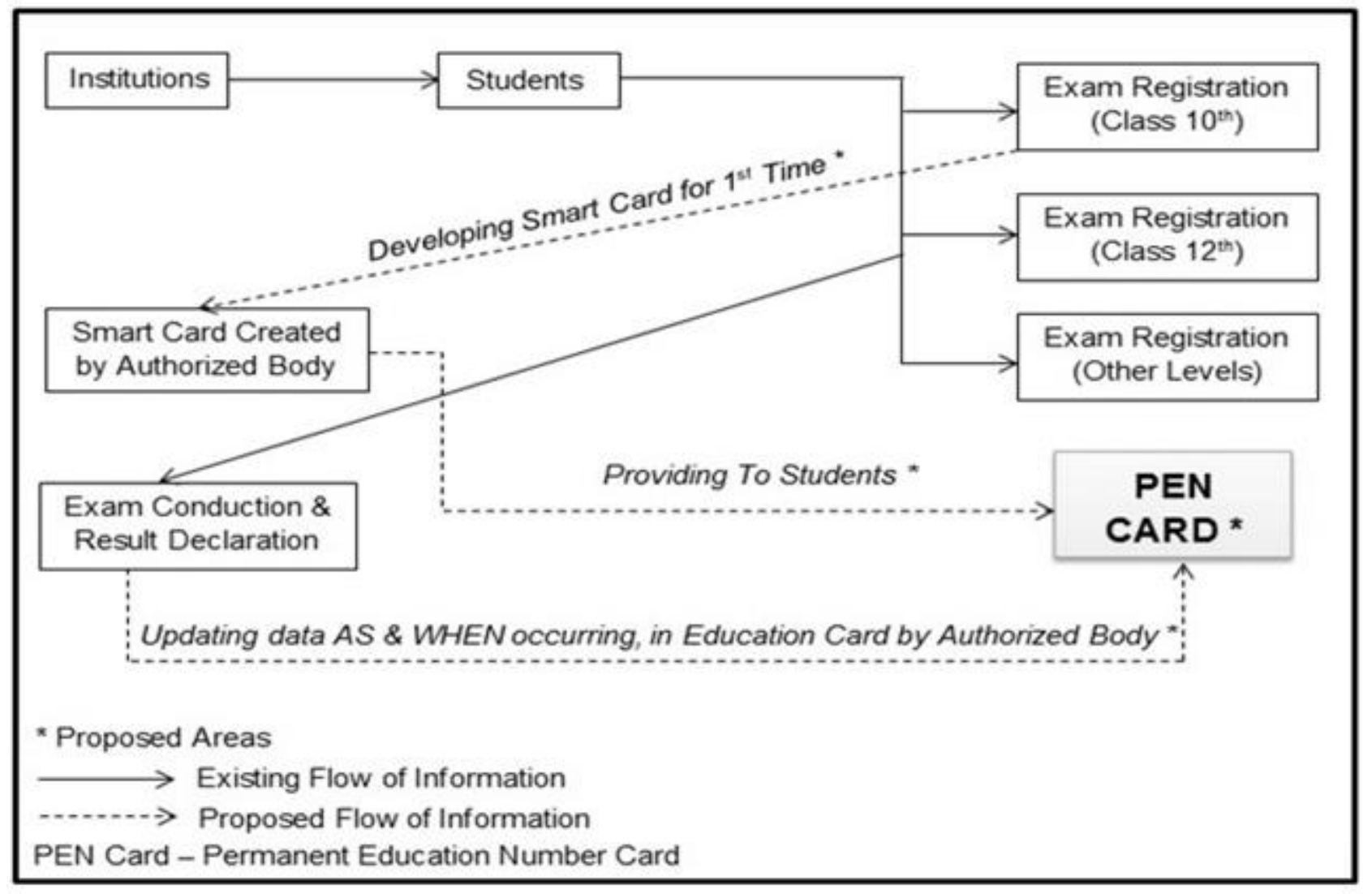

Figure 3. Proposed Conceptual Framework of PEN. [19]

\section{BENEFITS OF THE PROPOSED PEN CARD \& RESULTS}

After the implementation of the PEN card system in many of the difficulties and complications will be solved in the education and job sectors. It can be classified as follows: -

1. There will be no need to perform any sort of difficult activities by the Government to obtain the analytical figures regarding literacy.

2. Therefore, if the government can determine the exact details of literacy progress in the country or the states, it will not need to do much activity to gather data.

3. The expenses and time consumed in the abovementioned process can be used for some other fruitful events by the Government.

4. Communication between different education and employment organizations will be less tedious and the transparency will also be maintained in this procedure.

5. Students will not need to pass through the tiresome process of photocopying the numerous education credentials and testimonials at the time of admission or recruitment process every single time.
6. Most of the education credentials and testimonials will be present on the PEN card. So submitting a single photocopy of the PEN Card will be enough.

7. A huge percentage of the money needed for photocopying will be saved and can be used for some other activates by the students.

8. The paper usage ratio will drop at a huge percentage.

9. Difficultness in preserving the past student records for a long period for further use will be stress-free.

10. Space required for keeping the photocopies and the cost of maintaining the photocopies will be condensed.

11. The hold backspace and cost can be used for some other fruitful purposes.

12. The verification process of the education credentials and testimonials will be transparent and easy.

13. Falsification of the education credentials and testimonials will hardly occur, reduced.

14. The PEN card system will lead to a higher accuracy rate in the education and job sector's admission and recruitment process respectively.

15. The environment can also be protected to a greater extent by saving papers 


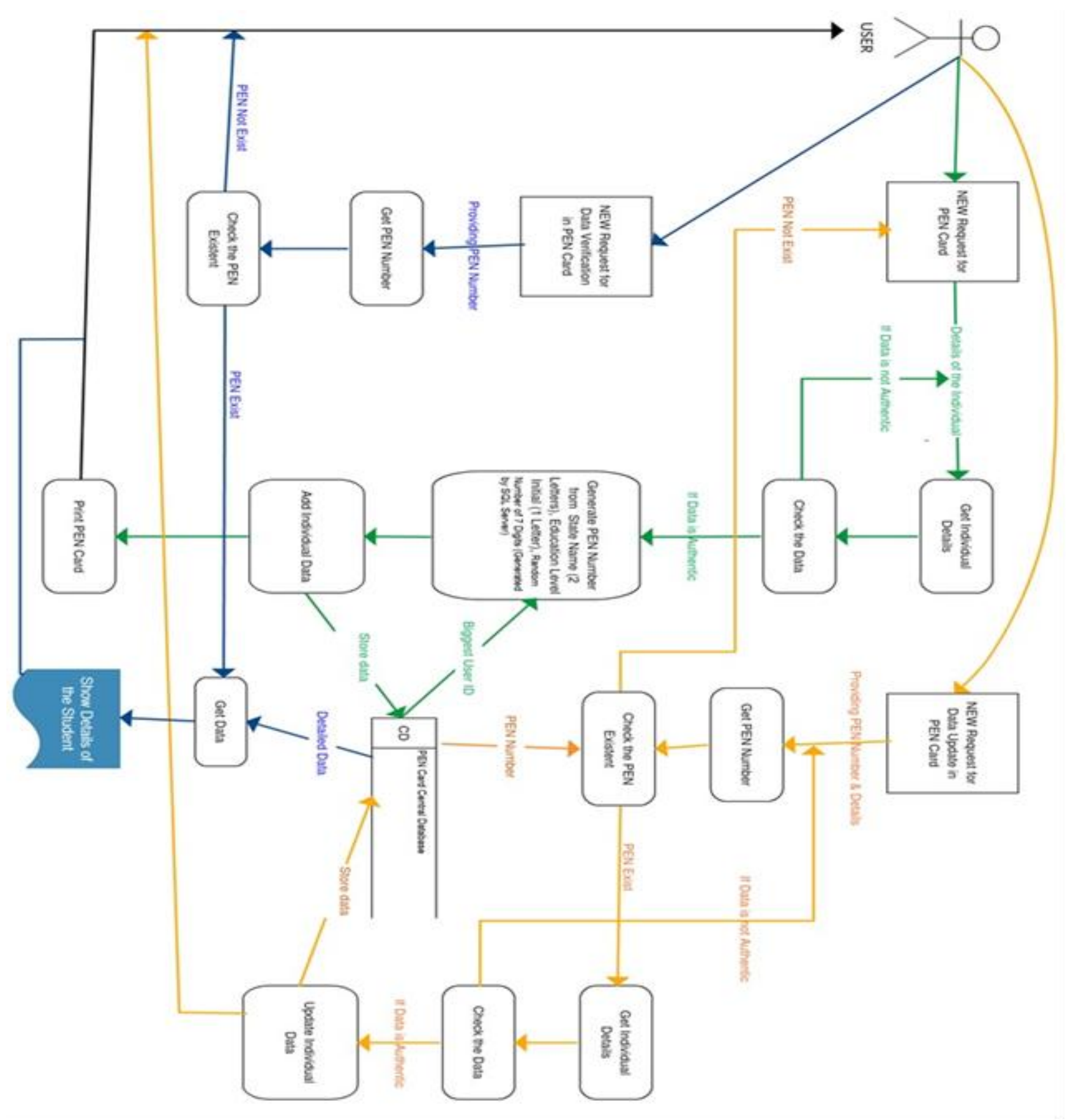

Figure 4. Data Flow Diagram of PEN Card System.

\section{CONCLUSION}

In both scenarios, students and candidates must physically present the original credentials to verify the authenticity of the hiring process. The number of documents used increases as students and applicants apply to more than one university or institution for admission, or job after completing graduation, which is a common practice among students and candidates in the Indian context. The PEN card contains all records of a particular student and can only be used to justify all the testimony of a particular student. The educational card is presented to Grade 10 students at the time of registration for the exam. As a result, the likelihood of submitting false identifiers and identifiers is reduced and students are not required to provide their original credentials and credentials for the review process.

\section{REFERENCES}

1. Hendry, M. (2001). Smart card security and applications. Boston, Mass.: Artech House.

2. Finkenzeller, K. (2003). RFID handbook: Fundamentals and applications in contactless smart cards and identification (2nd ed.). Chichester, England: Wiley.

3. Rankl, W., \& Effing, W. (2007). Smart card handbook (3rd ed.) (K. Cox, Trans.). Chichester: John Wiley \& Sons.

4. Ghosh, R. K., \& Ghosh, M. (2016, June). A Conceptual Framework for Adoption of Education Card in India Student's Perception. Pacific Business Review International, 1(1), 35-43. Retrieved from http://www.pbr.co.in/2016/2016_month/June/4.pdf 


\section{BLUEPRINT OF PERMANENT EDUCATION NUMBER (PEN) CARD FOR REDUCING PAPER USAGE RATIO IN EDUCATION AND JOB SECTOR}

5. Ghosh, R. K. (2018). Exploration of Perception Model for Acceptance of Digitalizing Education Credentials in Indian Education System. Tech Vistas A Quarterly Online Journal, 1(1), 55-70. Retrieved June 13, 2019, from http://techvistas.wbut.ac.in/paper5.php

6. Behl, A. (2017, March 20). Four held in Gurgaon for selling fake university degrees, marksheets. Retrieved July 19, 2019, from https://www.hindustantimes.com/gurugram/four-held-ingurugram-for-selling-fake-university-degreesmarksheets/story-1frqeDBKVwcrVuJNYJv4YP.html

7. Tnn. (2016, June 17). 122 students paid Rs 30L for fake degrees: Rajkot News - Times of India. Retrieved July 19, 2019, from http://timesofindia.indiatimes.com/city/rajkot/122students-paid-Rs-30L-for-fakedegrees/articleshow/52788630.cms?TOI_browsernotifica tion=true

8. Ghosh, R. K., Das, A., \& Bandyopadhyay, S. K. (2019). A Study to Identify the Adoption Intention of PEN Card amongst Diverse Groups. International Journal of Recent Technology and Engineering, 8(1C2), 1190-1197. Retrieved July 31, 2019, from https://www.ijrte.org/wpcontent/uploads/papers/v8i1C2/A12110581C219.pdf. Retrieval Number: A12110581C219/19@BEIESP

9. How Much Information 2003? (2003, October 30). Retrieved July 19, 2019, from http://groups.ischool.berkeley.edu/archive/how-muchinfo-2003/

10. Wilfred. (2005, October 07). Grams/square meter to pounds/ream. Retrieved July 19, 2019, from http://www.onlineconversion.com/forum/forum_1118773 419.htm

11. Paper density. (2015, January 12). Retrieved July 19 , 2019, from https://en.wikipedia.org/w/index.php?title=Paper density \&oldid $=643195757$

12. Paper size. (2015, January 6). Retrieved July 19, 2019, from

http://en.wikipedia.org/w/index.php?title=Paper_size\&ol did=641280319

13. 17 facts: Why you should NOT use paper. Retrieved July 19, 2019, from https://moreapp.com/en/blog/paper-facts/

14. Martin, S. (2011, November 15). Paper Chase. Retrieved July 19, 2019, from http://www.ecology.com/2011/09/10/paper-chase

15. Paper Waste Facts. (2014, May 13). Retrieved July 20, 2019, from http://www.theworldcounts.com/stories/Paper-WasteFacts

16. 7 The Pulp and Paper Industry. National Academy of Engineering and National Research Council. 1999. Industrial Environmental Performance Metrics: Challenges and Opportunities. Washington, DC: The National Academies Press. https://doi.org/10.17226/9458

17. Lee, C., Cheng, Y., and Depickere, A. (2003). Comparing smart card adoption in Singapore and Australian universities. Int. J. Human-Computer Studies, 58 (3), 307-325.

18. Aubert, B. A. and G. Hamel (2001). Adoption of smart cards in the medical sector: the Canadian experience. Social Science \& Medicine 53 (7): 879-894.

19. Ghosh, R. K., \& Adhikary, R. (2018). Design of EGovernment Framework for Acceptance of Education Card in Indian Education System. International Journal of Research in Management \& Social Science, 6(1), 128137. Retrieved June 13, 2019, from http://empyreal.co.in/downloads/ijrmss-volume6-issue1x-january-march-2018.pdf ISSN $2322-0899$ 